\title{
APLICAÇÃO DO MÉTODO LEAN SEIS SIGMA NO REUSO DO EFLUENTE TRATADO - ESTUDO DE CASO: FABRICAÇÃO DE PAPEL TISSUE
}

\section{LEAN SIX SIGMA METHODOLOGY APPLIED IN EFFLUENT REUSE - CASE STUDY: TISSUE PAPER MANUFACTURE}

Naiara Machado

Casagrande

Universidade Federal de Santa Catarina - UFSC,

Florianópolis/SC, Brasil. E-mail:

naiara.casagrande.nc@gm ail.com br

\section{Vanessa Monteiro}

Engenheira Ambiental, Universidade da Região de Joinville - UNIVILLE, Joinville/SC, Brasil. E-mail: nessaa_rm@hotmail.com

Nadja Zim Alexandre

Mestre em Geografia, Universidade Federal de Santa Catarina - UFSC, Florianópolis/SC, Brasil. E-mail:

nadjaalexandra@ima.sc.go v.hr

\section{RESUMO}

O setor de produção de papel é um grande consumidor de água, por isto foi desenvolvido este projeto com intuito de aumentar a taxa de reuso do efluente tratado. O objetivo é atender a demanda de água da empresa, que produz em média 150 toneladas de papel tissue diariamente. $\mathrm{O}$ estudo foi desenvolvido por meio de uma metodologia que busca as oportunidades de melhorias no processo, Lean Seis Sigma. A metodologia considerou a máquina de papel como o cliente da estação de tratamento de efluentes. A partir daí, com auxílio dos responsáveis pela estação, foram apontadas as principais variáveis que influenciam na qualidade da água, por meio de um brainstorming. Avaliou-se o grau de importância de cada uma destas variáveis em relação a parâmetros préestabelecidos que devem ser atingidos para garantir a recirculação com segurança na qualidade da água. Com a confecção de um diagrama de Pareto, foram obtidos os modos de falha mais críticos, do mesmo modo com o auxílio dos 5 por quês, foram investigadas as causas das falhas a fim de se encontrar soluções. Por fim, a implementação das melhorias propostas pelo projeto refletiu na obtenção de água para reuso com qualidade e condições exigidas pelo processo.

Palavras-chave: Lean manufacturing, Seis sigma, Reuso, Efluente, Papel.

\section{ABSTRACT}

The sector of paper production is a major consumer of water. Therefore, this work was developed in order to increase the rate of reuse of the treated effluent. To achieve the demand of water for the company, an amount of water has been took from a river near the plant. Therefore, effluent recirculation helps the reduction on freshwater demand, preserving this natural resource. The purpose of the study was achieved by applying a methodology that seeks opportunities for process improvement and it is called Lean Six Sigma. In this study, the paper machine was considered the customer of the effluent treatment plant. Afterwards, the knowledge who work on the effluent treatment plant contributed for a brainstorming to identify the main process and equipment variables that influence in the water quality. Then, their importance were assessed and linked to parameters that must be reached to ensure the recirculation. In the sequence, the utilization of a Pareto diagram showed the most critical failure modes. In the same way, their causes were investigated to find solutions by the " 5 reasons". Finally, the installation of proposed advancements guaranteed the water quality and the conditions required by the process for reuse.

Keywords: Lean manufacturing, Reuse, Effluent, Paper. 


\section{INTRODUÇÃO}

A indústria de fabricação de papel é uma grande consumidora de água durante a etapa de preparação do seu produto, tendo como principal equipamento do processo produtivo a Máquina de Papel. Esta, tem como função remover a água da suspensão de fibras proveniente do circuito de preparação de massa e formar a folha de papel. Este equipamento é basicamente constituído por quatro seções: Formação, Prensagem, Secagem e Enroladeira (BARROS, 2006). Durante todo este processo, a fabricação de papel gera efluente com elevada carga de matéria orgânica, devido à presença de celulose dissolvida e em suspensão na sua composição.

Segundo Telles e Costa (2007) o reuso do efluente tratado vem como uma alternativa sustentável para o setor. Sendo que, este pode ser realizado na própria planta geradora do efluente, após a passagem do mesmo por um sistema de tratamento, de modo a adequar a qualidade da água àquela demandada no processo. A recirculação do efluente tratado pode ocorrer de forma direta ou indireta, por meio de ações planejadas ou não. Para isto, a primeira consideração que se aconselha verificar é quanto à presença de microrganismos patogênicos, garantindo que esses não estejam presentes na água em densidade que represente um risco significativo para saúde dos usuários (MANCUSO; DOS SANTOS, 2003).

Para fabricação de papel Tissue são utilizados em média $16 \mathrm{~m}^{3}$ de água por tonelada de papel produzido. Por ser um volume alto, é importante o desenvolvimento de estudos de elevação do percentual de reuso interno, reduzindo a captação de água do meio natural. Sendo assim, o estudo considerou a possibilidade de aumento do reuso do efluente na máquina de papel, logo, encontra-se focado na estação de tratamento de efluentes (ETE) e nos requisitos de qualidade da água exigidos para operação da máquina.

Santos Filho (1987) informa que em geral a qualidade da água para a indústria de papel varia de acordo com a qualidade do produto requerido, podendo utilizar desde água comum, tipo potável, até água desmineralizada. Sendo assim, neste estudo de caso, de uma indústria de fabricação de papel tissue, procurou-se elevar a média de reuso, considerando a manutenção da qualidade da água fornecida para atender aos indicadores da Máquina de Papel. Para isto, foram utilizadas ferramentas que auxiliam a tomada de decisão, Lean e Seis Sigma.

A associação destas duas ferramentas, permite um maior nível de eficiência para desenvolvimento do projeto e garantia no controle de qualidade. Enquanto o Lean tem foco na eliminação de desperdícios ao longo do processo, o Seis Sigma prevê o aumento da qualidade e redução de variabilidade dos processos críticos buscando a garantia da satisfação do cliente, que neste caso é a máquina de papel (EDWARD; MALEYEFF, 2005). 


\section{MEDODOLOGIA}

O estudo descreve a situação evidenciada em uma empresa de grande porte, com participação significativa no mercado de higiene pessoal no Brasil, produzindo em média 150 toneladas de papel tipo tissue diariamente. O processo envolve, basicamente, os setores onde ocorre o preparo da massa, as operações da Máquina de Papel e a Estação de Tratamento de Efluentes (ETE). Somando a água que entra para o processo produtivo nestas duas primeiras etapas, tem-se uma média de consumo na ordem de $16 \mathrm{~m}^{3}$ por tonelada de papel produzido.

\section{Estação de tratamento de efluentes}

A água utilizada no processo, bem como o efluente gerado, seguem para a ETE com a finalidade de torná-los com características que atendam à Resolução CONAMA n 430/2011 (CONAMA, 2011). Sendo que, essa dispõe sobre condições e padrões de lançamento de efluentes no Brasil. A estação de tratamento de efluentes na empresa estudada é composta por processos químicos e biológicos, representados na Figura 1.

Figura 1: Fluxo do processo de tratamento de efluentes da indústria de estudo de caso.

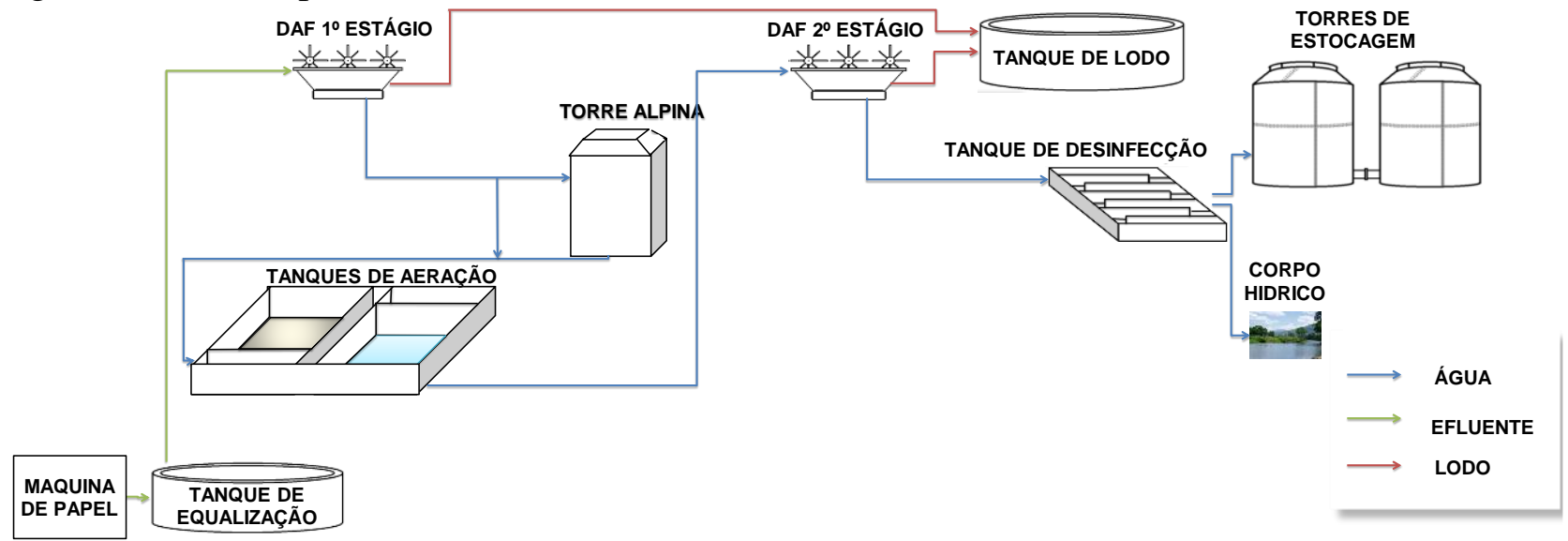

Fonte: Empresa do estudo de caso, 2015.

A ETE tem capacidade de tratar $315 \mathrm{~m}^{3} / \mathrm{h}$ e a unidade descarta em média $53.000 \mathrm{~m}^{3} / \mathrm{mês,}$ com percentual de tratamento de $100 \%$ do efluente gerado e eficiência de remoção próxima a $90 \%$, avaliando-se as características físicas e químicas.

\section{IMPLEMENTAÇÃO DA METODOLOGIA DMAIC}

O estudo para aumento da recirculação do efluente tratado foi realizado em 5 etapas, conforme o método DMAIC, utilizado para guiar o projeto Lean Six Sigma. As etapas foram: definir, medir, analisar, melhorar e controlar (MOUSA, 2013). 


\section{Definição de "baseline”}

A primeira etapa constituiu da definição de meta no incremento na taxa de reuso do efluente. Para tanto, teve-se como base um aumento de $70 \%$ da vazão de reuso do melhor período relatado pelo histórico de reaproveitamento de efluente tratado, sem risco ao processo produtivo. A Figura 2 mostra que a taxa de reuso de $16,5 \%$ é suficiente para cumprir a meta estabelecida, sendo então, definida como baseline para as próximas etapas.

Figura 2: Histórico do percentual de recirculação e estabelecimento de meta de taxa $(16,5 \%)$ para recirculação no projeto.

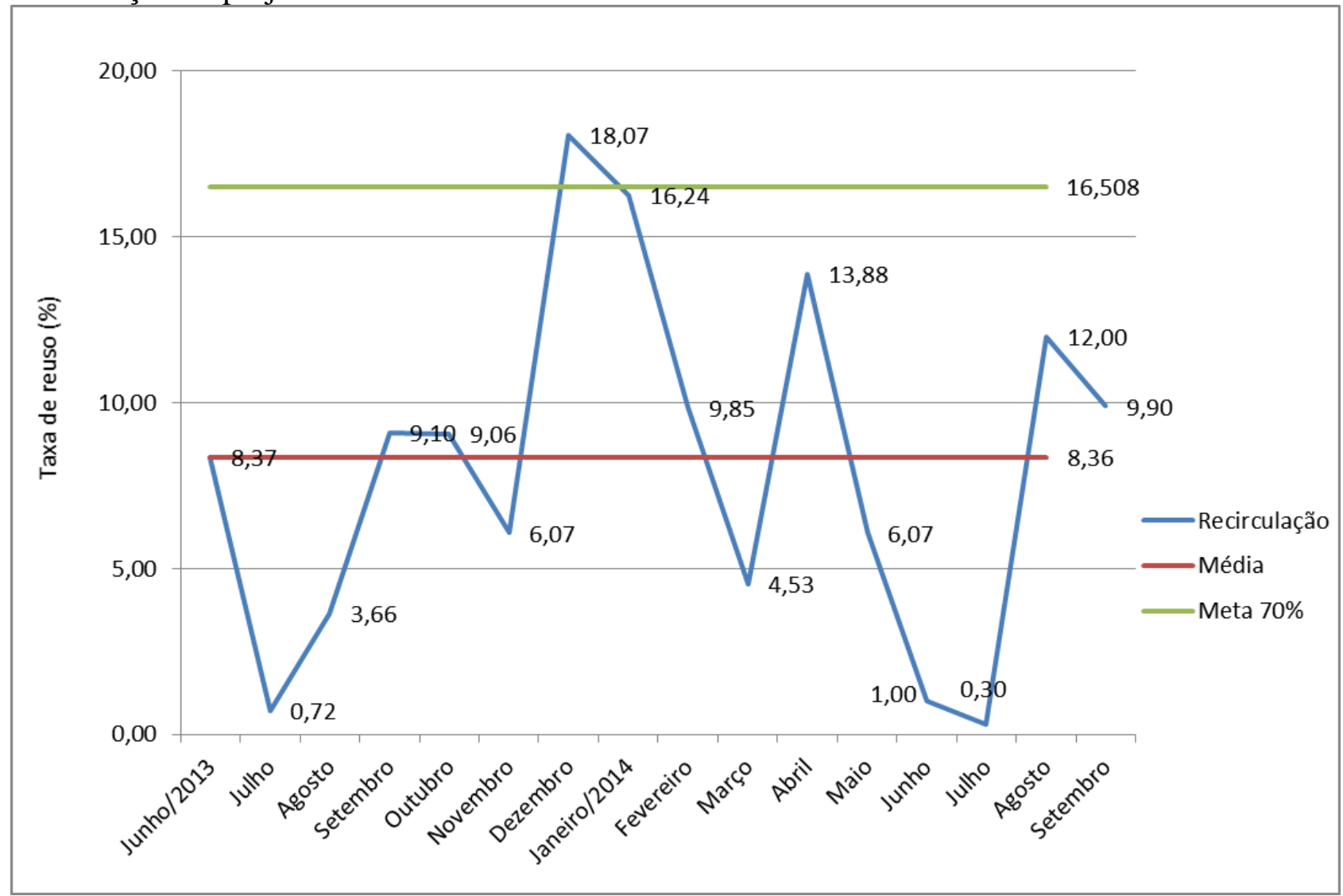

Fonte: Empresa do estudo de caso, 2015.

\section{Parâmetros Físico-Químicos para recirculação do efluente}

Tendo em vista que parte do efluente tratado será reutilizada e parte continuará sendo descartada no corpo receptor, é importante que se cumpram as exigências legais associadas e as condições necessárias para o reuso e descarte. Por isto, na sequência, foram definidos limites de parâmetro de qualidade da água, exigidos pela máquina de papel.

Quanto à destinação de reuso, os parâmetros devem estar em conformidade com os limites máximos e mínimos estabelecidos. As características físico-químicas de maior influência para o 
processo produtivo da empresa, foram chamadas de parâmetros "y" e seus respectivos valores esperados podem ser vistos na Tabela 1.

Tabela 1: Parâmetros físico-químicos para recirculação de efluente.

\begin{tabular}{|c|c|c|c|c|c|}
\hline Seção & Subseção & Item $(y)$ & Unidade & Min & Max \\
\hline \multirow{4}{*}{ Recirculação efluente } & \multirow{4}{*}{$\begin{array}{l}\text { Tanque de } \\
\text { desinfecção }\end{array}$} & Turbidez & NTU & 0,1 & 7 \\
\hline & & Residual de Cloro & $\mathrm{mg} / \mathrm{L}$ & 0,01 & 0,1 \\
\hline & & $\mathrm{pH}$ & - & 6,5 & 8,5 \\
\hline & & SST & $\mathrm{mg} / \mathrm{L}$ & 5 & 40 \\
\hline
\end{tabular}

Fonte: Empresa do estudo de caso, 2015.

Dentre as características apresentadas na Tabela 1, a turbidez, o residual de cloro e o pH são consideradas as mais críticas por interferirem diretamente no processo em questão. Quanto ao valor do residual de cloro, é importante para manter o controle biológico do efluente, garantindo que microrganismos patogênicos não estejam presentes na água. Ao mesmo tempo se o $\mathrm{pH}$ estiver baixo, pode causar problemas de corrosão nas máquinas e equipamentos, e quando alto, poderá reagir com os outros produtos químicos utilizados no processo. A turbidez, que também está ligada aos Sólidos Suspensos Totais, pode causar a saturação da água no processo, portanto é julgado seguro trabalhar com a turbidez mais baixa possível, ou próxima da água potável.

\section{Principais variáveis de controle para reuso da água no processo}

Para determinação das variáveis de maior relevância e identificação dos pontos críticos, foi elaborado o Mapa de Variáveis " $\mathrm{x}$ ". O mapa serve para relacionar as principais sub-etapas do processo industrial e as oscilações de saída e entrada do sistema de tratamento de efluentes. Este foi dividido em 6 (seis) temas estratégicos: Materiais, Medidas, Máquina, Mão de Obra, Método e Meio Ambiente. Em um brainstorming com os conhecedores da operação do sistema de ETE, foram levantados os principais pontos que influenciam em cada um destes temas.

\section{Elaboração da Matriz de Causa e Efeito}

Após o mapeamento de todas as variáveis "x”, atribuiu-se grau de importância com relação aos parâmetros " $y$ " definidos para recirculação do efluente, considerados como indicadores fundamentais na qualidade da água. Uma matriz correlacionando as variáveis com os parâmetros foi construída, estimando-se quais " $\mathrm{x}$ " podem afetar cada um destes " $y$ ", e ao mesmo tempo foi definido um valor de 1 a 10 conforme sua importância nas características de qualidade do produto final. 
A escala para o grau de correlação foi definida como: 0 (nenhuma correlação), 1 (pouca correlação), 3 (alguma correlação) até 9 (muita correlação). Já na etapa seguinte, contemplou-se as somas ponderadas das linhas dos " $\mathrm{x}$ " para adquirir o valor Total de cada uma das variáveis. Posteriormente, foi utilizada a estratificação com o auxílio de um gráfico de barras para indicação dos parâmetros e interações mais significativas e consequentemente priorização das mesmas.

\section{Análise dos modos de falha e efeito}

A análise dos modos de falha e efeito contribuiu para o levantamento de possíveis problemas de produtos e processos objetivando a prevenção da ocorrência destes e aumento da segurança e satisfação do cliente final, a Máquina de Papel. Neste caso, foram revisados os modos de falha e identificados seus efeitos potenciais de ocorrência. A partir dos efeitos foram definidos valores de Severidade, Ocorrência e Detecção, conforme mostra a Tabela 2.

Tabela 2: Dados de definição: Grau de Severidade, Ocorrência e Detecção do modo de falha.

\begin{tabular}{cccc}
\hline Grau & Grau de severidade & Ocorrência & Detecção \\
\hline 1 & Nenhuma & Extremamente remota & Quase certa \\
2 & Muito insignificante & Muito remota & Muito alta \\
3 & Insignificante & Remota & Alta \\
4 & Muito baixa & Muito baixa & Moderadamente alta \\
5 & Baixa & Baixa & Moderada \\
6 & Moderada & Moderada & Baixa \\
7 & Alta & Moderadamente alta & Muito baixa \\
8 & Muito alta & Elevada & Remota \\
9 & Extremamente alta & Muito elevada & Muito remota \\
10 & Perigosamente alta & Ocorrência certa & Absolutamente incerto \\
\hline
\end{tabular}

Fonte: Empresa do estudo de caso, 2015.

Inicialmente os modos de falhas, foram classificados refletindo a gravidade dos mesmos, então foram definidas suas chances de ocorrência. Na sequência, a lista dos valores de Detecção dos modos de falhas, ajudou a encontrar qual é a chance de não detectar os mesmos ou as causas que resultam destes. Finalmente, para realizar o cálculo do grau de prioridade de risco (RPN), multiplicam-se os índices de Severidade, Ocorrência e Detecção. Com estes valores do RPN definidos foi construído um Pareto visando a priorização dos modos de falha. 


\section{Priorização das variáveis}

Na priorização das variáveis foi utilizado do Diagrama de Pareto, onde por meio deste tornase visível a ação que trará um resultado mais expressivo. Para construção do Pareto foram colocados em ordem decrescente os Totais das variáveis " $x$ ", permitindo assim uma visão estratégica das variáveis mais críticas.

\section{Análise de Causa Raiz}

$\mathrm{Na}$ análise da causa raiz, foram relacionados os modos de falha definidos e discutidos porque esta condição está ativa. Os 5 por quês foram questionados em conjunto com os interessados do processo e colaboradores de maior experiência, para se chegar às causas raízes potenciais e por fim buscar soluções trabalhando com exatidão na causa principal de possíveis falhas.

\section{RESULTADOS E DISCUSSÃO}

A construção do Mapa de Variáveis, a fim de conhecer as principais variáveis que afetam os padrões das propriedades da água, totalizou em 23 variáveis “ $x$ ”, a serem avaliadas e distribuídas entre Materiais, Medidas, Máquina, Mão de Obra, Método e Meio Ambiente. O Mara de variáveis resultou na Tabela 3 .

Tabela 3: Mapa de variáveis de relevância no processo.

\begin{tabular}{lll}
\hline Etapas & X & \\
\hline Materiais & X1 & Qualidade do produto químico \\
x2 & Falta do produto químico \\
x3 & Conhecimento técnico equiparado/nivelado \\
x4 & Aplicação incorreta do produto químico \\
x5 & Manuseio incorreto de equipamentos \\
x6 de Obra & Treinamento da equipe. \\
x7 & Drenagem dos taques da MP \\
x8 & Lavação dos tanques da MP \\
x9 & Limpeza química na MP \\
x10 & Carga iônica do efluente \\
x11 & Vida útil do Equipamento \\
x12 & Eficiência dos equipamentos \\
x13 & Check list preventivo de manutenção \\
x14 & Falha no equipamento \\
x15 & Falha na calibração dos equipamentos de medição \\
x16 & Dosagem de produtos químicos \\
x17 & Procedimentos de coleta e análises \\
Máquina &
\end{tabular}


x18 Residual de cloro

Medidas $\quad \mathrm{x} 19 \mathrm{pH}$

x20 Turbidez

x21 Temperatura

x22 Sólidos sedimentáveis

x23 Sólidos suspensos totais

Fonte: do autor, 2015.

Com as variáveis definidas o próximo passo foi a avaliação dos seus respectivos graus de importância e correlação destas com os parâmetros principais do efluente. O resultado desta estimativa pode ser visto na Tabela 4.

Tabela 4: Variáveis do processo que influenciam na recirculação.

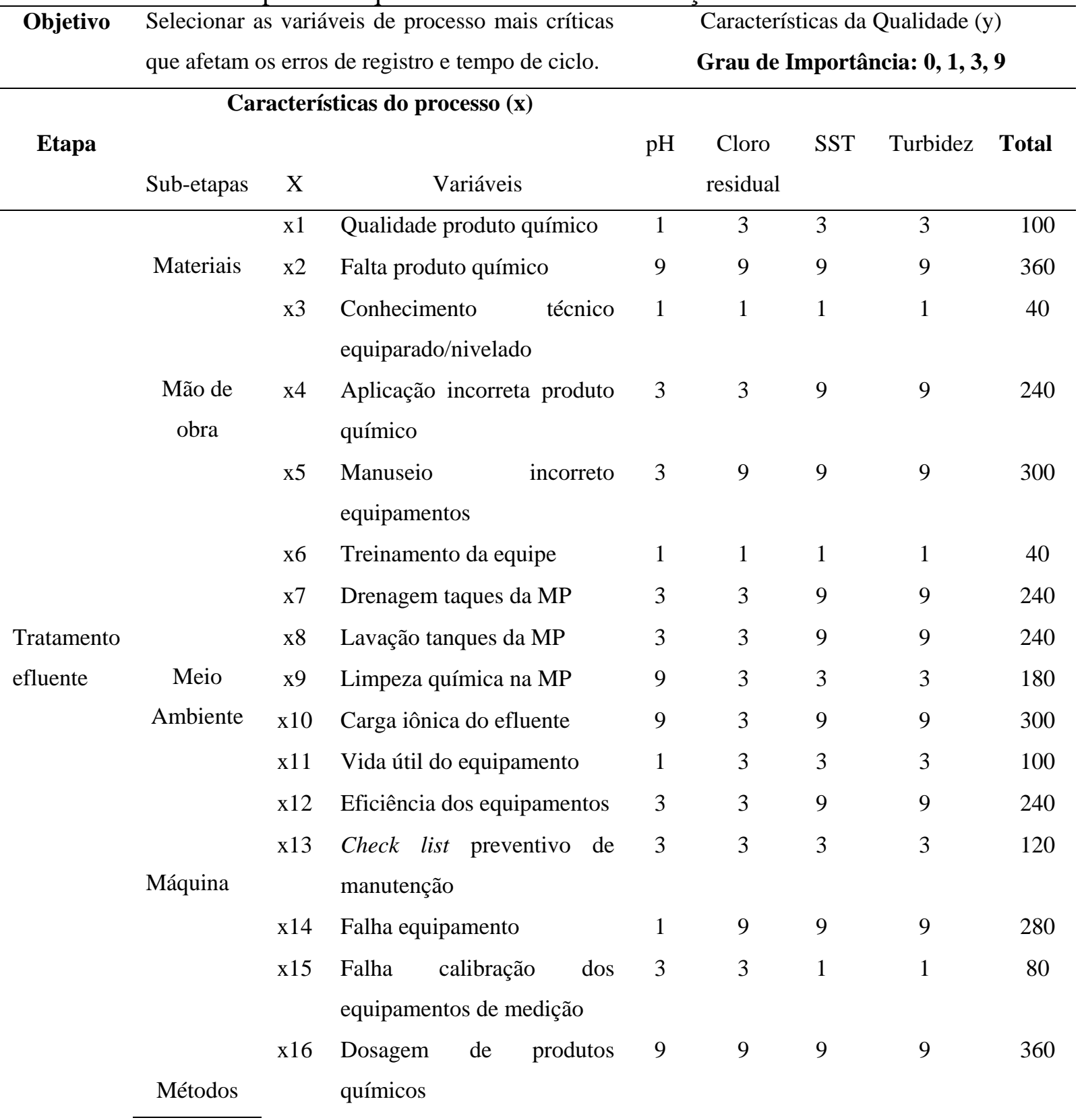


Revista Tecnologia e Ambiente, v. 25, 2019, Criciúma, Santa Catarina/SC ISSN Eletrônico 2358-9426 e ISSN Impresso 1413-8131

\begin{tabular}{rlllllll}
\multicolumn{1}{c}{ x17 } & Procedimentos de coleta e & 3 & 3 & 3 & 3 & 120 \\
& & análises & & & & & \\
x18 & Residual de cloro & 3 & 0 & 0 & 0 & 30 \\
x19 & pH & 0 & 1 & 3 & 3 & 70 \\
& x20 & Turbidez & 0 & 3 & 3 & 0 & 90 \\
& x21 & Temperatura & 1 & 3 & 1 & 0 & 50 \\
& x22 & SS & 0 & 3 & 3 & 3 & 90 \\
x23 & SST & 0 & 3 & 0 & 3 & 60 \\
\hline
\end{tabular}

Fonte: do autor, 2015.

A fim de priorizar as variáveis “ $x$ ”, que apresentaram os maiores valores no Total, seguiu-se com a construção do gráfico de estratificação dos "x", conforme apresentado na Figura 3.

Figura 3: Estratificação das variáveis " $\mathrm{x}$ " apontadas como principais causas da instabilidade do processo e que influenciam no reuso de água.

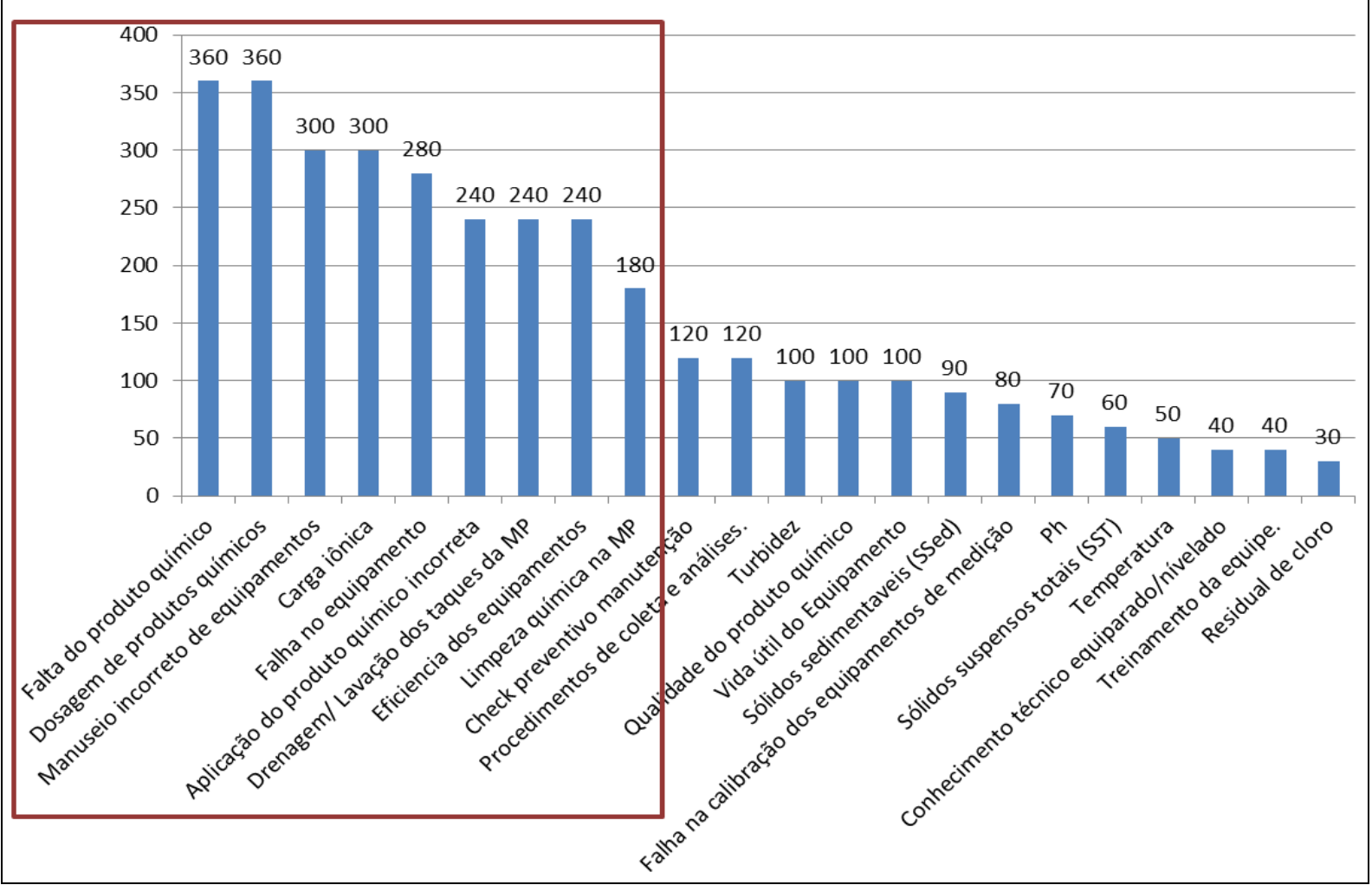

Fonte: do autor, 2015.

Como pode ser visto na Figura 3, as variáveis de maior relevância, ou seja, as mais influentes no processo e que seguiram para a próxima etapa, foram aquelas com valores acima de 180, marcadas pelo retângulo no gráfico.

Estas informações foram utilizadas para contemplar na sequência, o processo de análise de modos de falha e efeito, ou seja, a Matriz de Causa e Efeito. Para tanto, atribui-se valores de 
Revista Tecnologia e Ambiente, v. 25, 2019, Criciúma, Santa Catarina/SC ISSN Eletrônico 2358-9426 e ISSN Impresso 1413-8131

Severidade, Ocorrência e Detecção para as variáveis "x" de maior expressão no Pareto. O resultado desta etapa originou a Tabela 5. 
Revista Tecnologia e Ambiente, v. 25, 2019, Criciúma, Santa Catarina/SC ISSN Eletrônico 2358-9426 e ISSN Impresso 1413-8131

Tabela 5: Etapas do processo e análise dos modos de falha e efeito.

\begin{tabular}{|c|c|c|c|c|c|c|c|c|}
\hline \multirow{2}{*}{ Etapas } & Modos de falha & Efeitos & Severidade & Causas & Ocorrência & $\begin{array}{l}\text { Controles } \\
\text { Existentes }\end{array}$ & Detecção & RPN \\
\hline & Quais as entradas? & $\begin{array}{c}\text { Qual impacto no } \\
\text { cliente? }\end{array}$ & $\begin{array}{c}\text { Gravidade } \\
\text { do efeito }\end{array}$ & $\begin{array}{c}\text { Quais são as causas dos } \\
\text { modos de falha? }\end{array}$ & $\begin{array}{r}\text { Frequência } \\
\text { das causas }\end{array}$ & $\begin{array}{c}\text { Como são } \\
\text { detectados? }\end{array}$ & $\begin{array}{l}\text { Chance de } \\
\text { ñ detecção }\end{array}$ & Resultado \\
\hline \multirow{7}{*}{$\begin{array}{l}\text { Produto } \\
\text { químico }\end{array}$} & & & 8 & Falta do produto químico & 2 & $\begin{array}{l}\text { Parâmetros fora } \\
\text { do limite }\end{array}$ & 1 & 16 \\
\hline & $\begin{array}{l}\text { Falta de produto } \\
\text { guímico }\end{array}$ & $\begin{array}{l}\text { Formação de } \\
\text { colônias }\end{array}$ & 8 & Falha na bomba & 2 & Inspeção visual & 2 & 32 \\
\hline & & & 8 & Falha de monitoramento & 1 & $\begin{array}{l}\text { Parâmetros fora } \\
\text { do limite }\end{array}$ & 2 & 16 \\
\hline & Dosagem de produtos & $\begin{array}{l}\text { Formação de } \\
\text { colônias }\end{array}$ & 10 & Falha na bomba & 2 & $\begin{array}{l}\text { Inspeção visual/ } \\
\text { parâmetros fora } \\
\text { do limite }\end{array}$ & 1 & 20 \\
\hline & $\begin{array}{c}\text { quimicos (baixa ou } \\
\text { alta) }\end{array}$ & $\begin{array}{l}\text { Corrosão de } \\
\text { equipamentos }\end{array}$ & 10 & Falha de monitoramento & 1 & $\begin{array}{l}\text { Inspeção visual/ } \\
\text { parâmetros fora } \\
\text { do limite }\end{array}$ & 1 & 10 \\
\hline & $\begin{array}{l}\text { Aplicação incorreta do } \\
\text { produto químico }\end{array}$ & $\begin{array}{l}\text { Redução da } \\
\text { eficiência dos } \\
\text { químicos }\end{array}$ & 8 & $\begin{array}{l}\text { Aplicação incorreta do } \\
\text { produto químico }\end{array}$ & 1 & $\begin{array}{l}\text { Inspeção visual/ } \\
\text { parâmetros fora } \\
\text { do limite }\end{array}$ & 1 & 8 \\
\hline & $\begin{array}{c}\text { Manuseio incorreto de } \\
\text { equipamentos }\end{array}$ & $\begin{array}{l}\text { Dosagem } \\
\text { ineficiente }\end{array}$ & 8 & Vida útil do equipamento & 2 & Inspeção visual & 3 & 48 \\
\hline \multirow[t]{3}{*}{$\begin{array}{l}\text { Equipa- } \\
\text { mento }\end{array}$} & Falha no equipamento & $\begin{array}{l}\text { Dosagem } \\
\text { ineficiente }\end{array}$ & 10 & $\begin{array}{c}\text { Falta de manutenção } \\
\text { preventiva }\end{array}$ & 6 & Não existe & 10 & 600 \\
\hline & $\begin{array}{l}\text { Baixa eficiência do } \\
\text { equipamento }\end{array}$ & Não recirculação & 10 & $\begin{array}{c}\text { Falta de manutenção } \\
\text { preventiva }\end{array}$ & 6 & Não existe & 10 & 600 \\
\hline & Carga iônica & Não recirculação & 10 & Carga iônica & 10 & $\begin{array}{c}\text { Inspeção visual e } \\
\text { testes }\end{array}$ & 1 & 100 \\
\hline \multirow[t]{2}{*}{ Efluente } & $\begin{array}{c}\text { Drenagem/Lavação dos } \\
\text { tanques da MP }\end{array}$ & Alteração do pH & 6 & $\begin{array}{c}\text { Drenagem/Lavação dos } \\
\text { tanques da MP }\end{array}$ & 1 & Sem controle & 10 & 60 \\
\hline & $\begin{array}{c}\text { Limpeza química na } \\
\text { MP }\end{array}$ & Alteração do pH & 10 & Limpeza química na MP & 10 & Sem controle & 10 & 1000 \\
\hline
\end{tabular}

Fonte: do autor, 2015. 
Com a priorização no total de 9 (nove) modos de falha, estes foram organizados em um Pareto, Figura 4, com objetivo de concentrar esforços para controlar as variáveis de maior RPN, uma vez que é onde os problemas são mais significativos.

Figura 4: Priorização de modos de falha em ordem decrescente.

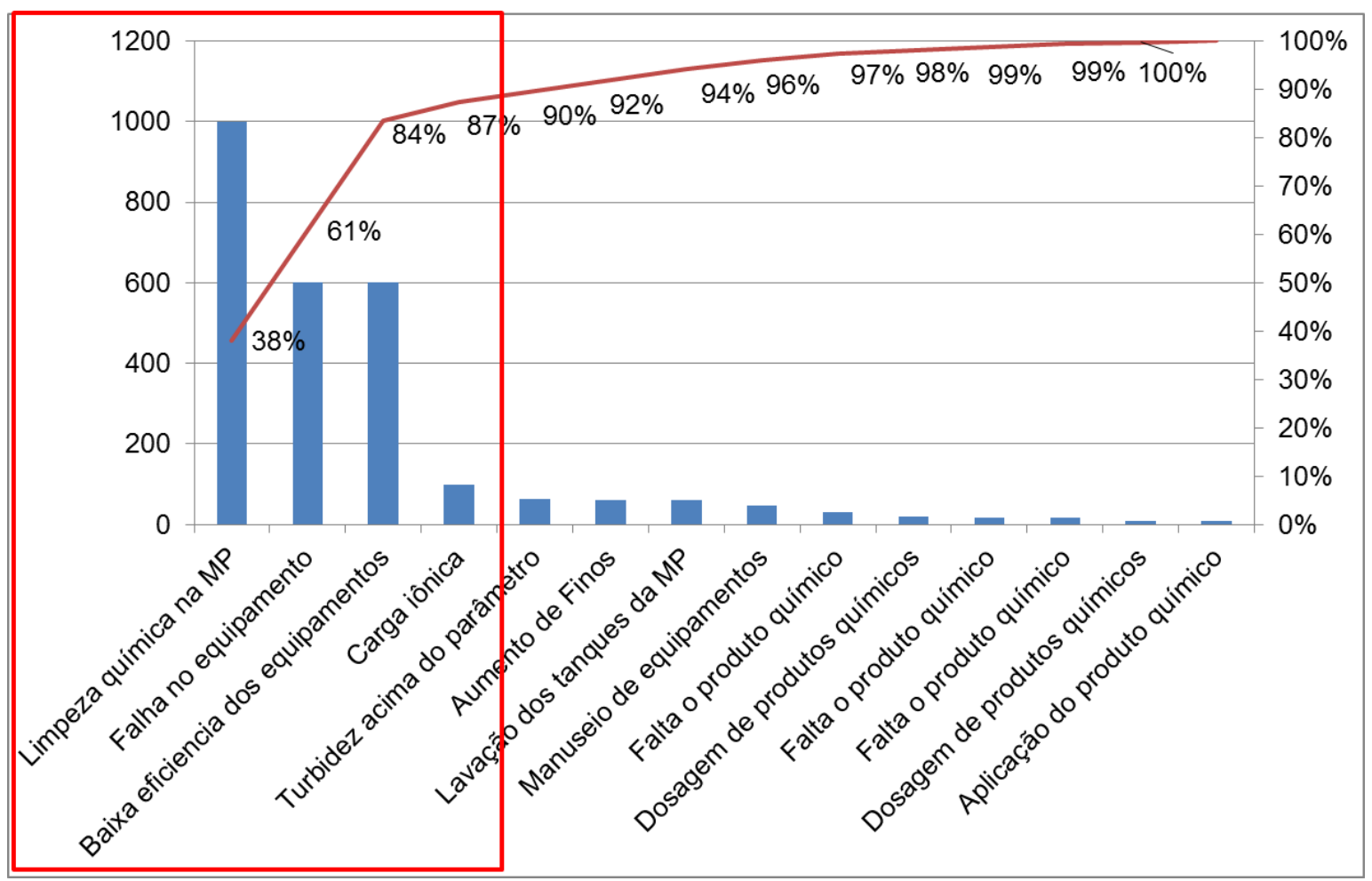

Fonte: do autor, 2015.

Conforme o Diagrama, os 4 primeiros modos de falha, representam 87\% das causas de falhas, o restante tem valores quase insignificantes comparados aos 4 (quatro) primeiros. Isto indica os modos de falha em que os esforços devem ser concentrados para maior eficácia do projeto. Os outros modos de falha

As quatro prioridades selecionadas foram para a análise de Causa Raiz, na qual foi elaborado um diagnóstico em conjunto com a equipe dos interessados do processo. Este diagnóstico resultou na análise dos 5 por quês, cujo resultado segue na Tabela 6 . 
Revista Tecnologia e Ambiente, v. 25, 2019, Criciúma, Santa Catarina/SC ISSN Eletrônico 2358-9426 e ISSN Impresso $1413-8131$

Tabela 6: Análise dos 5 por quês de cada modo de falha

\begin{tabular}{|c|c|c|c|c|c|c|c|}
\hline Modo de falha & $1^{\circ} \mathrm{POR} \mathrm{QUE}$ & $2^{\circ} \mathrm{POR} \mathrm{QUE}$ & $3^{\circ} \mathrm{POR}$ QUÊ & $4^{\circ} \mathrm{POR}$ QUÊ & $5^{\circ}$ POR QUÊ & Causa Raiz & Solução \\
\hline $\begin{array}{l}\text { Limpeza química } \\
\text { máquina de papel }\end{array}$ & $\begin{array}{l}\text { Condicionamento de } \\
\text { vestimentas da MP }\end{array}$ & $\begin{array}{c}\text { Necessidade do } \\
\text { processo }\end{array}$ & - & - & - & $\begin{array}{l}\text { Necessidade } \\
\text { do processo }\end{array}$ & $\begin{array}{c}\text { Adequar o sistema de } \\
\text { correção de } \mathrm{pH} \text { para atual } \\
\text { necessidade do processo }\end{array}$ \\
\hline $\begin{array}{c}\text { Falha no } \\
\text { equipamento }\end{array}$ & $\begin{array}{l}\text { Parada repentina: } \\
\text { elétrica ou mecânica/ } \\
\text { Ineficiência do } \\
\text { equipamento }\end{array}$ & $\begin{array}{l}\text { Desgaste, } \\
\text { rompimento, } \\
\text { quebra ou } \\
\text { sobrecarga. }\end{array}$ & $\begin{array}{l}\text { Falta de rotina } \\
\text { para inspecionar } \\
\text { os } \\
\text { equipamentos }\end{array}$ & $\begin{array}{c}\text { Falta de } \\
\text { manutenção } \\
\text { preventiva }\end{array}$ & - & $\begin{array}{c}\text { Falta de } \\
\text { manutenção } \\
\text { preventiva }\end{array}$ & $\begin{array}{c}\text { Definir frequência de } \\
\text { manutenção preventiva das } \\
\text { bombas. }\end{array}$ \\
\hline $\begin{array}{c}\text { Baixa eficiência dos } \\
\text { equipamentos }\end{array}$ & $\begin{array}{c}\text { Tanque de desinfecção } \\
\text { com rachaduras e } \\
\text { poroso }\end{array}$ & $\begin{array}{l}\text { Material de } \\
\text { construção } \\
\text { impróprio }\end{array}$ & Falha no projeto & & - & $\begin{array}{l}\text { Falha no } \\
\text { projeto }\end{array}$ & $\begin{array}{l}\text { Recuperação, pintura e } \\
\text { nivelamento do tanque. }\end{array}$ \\
\hline Carga iônica & $\begin{array}{c}\text { Necessidade de } \\
\text { correção de pH no } \\
\text { tanque de equalização }\end{array}$ & $\begin{array}{l}\text { Variação de pH } \\
\text { no tanque de } \\
\text { equalização }\end{array}$ & $\begin{array}{c}\text { Lavação } \\
\text { química na MP }\end{array}$ & $\begin{array}{l}\text { Ineficiência no } \\
\text { controle do pH } \\
\text { da MP }\end{array}$ & - & $\begin{array}{c}\text { Ineficiência no } \\
\text { controle do pH } \\
\text { da MP }\end{array}$ & $\begin{array}{c}\text { Adequar o sistema de } \\
\text { correção de pH para atual } \\
\text { necessidade do processo }\end{array}$ \\
\hline
\end{tabular}

Fonte: do autor, 2015. 
Com a revelação das possíveis Causas que poderiam estar originando ou vir a originar os modos de falha, foram estudadas possíveis soluções. Desta forma, foram propostas o total de três ações para sanar ou mitigar os quatro principais modos de falha.

\section{IMPLEMENTAÇÃO DAS AÇÕES DE MELHORIAS}

As soluções resumem-se em investir em melhorias e formas de controle no próprio processo de tratamento de efluentes. Para assim, se obter uma maior efetividade nos sistemas de dosagem de químicos, correção de $\mathrm{pH}$ do efluente antes de chegar ao tanque de equalização e também aumento da eficiência do tanque de desinfecção.

\section{Adequação do sistema de correção de pH}

O sistema de dosagem para correção do pH do efluente gerado na Máquina de Papel era considerado ineficiente, principalmente quando recebida uma grande carga de químicos. $\mathrm{O}$ controle de $\mathrm{pH}$ não atendia às necessidades devido às diversas intervenções manuais, realizadas pelos operadores do processo, no sistema. Quando havia alguma variação, o $\mathrm{pH}$ tinha que ser corrigido já no Tanque de Equalização, o que não é indicado, pois o volume de efluente é muito maior e qualquer erro poderia comprometer todo o sistema. Visando melhorar esta condição, uma possível solução foi deixar o efluente neutralizado no tanque anterior ao Tanque de Equalização da ETE, instalando um sistema automatizado, responsável por medir e regular a dosagem dos produtos para regular o $\mathrm{pH}$.

\section{Recuperação, pintura e nivelamento do tanque de desinfecção}

É comum o crescimento de limo na água recirculada, fato que pode vir a prejudicar a fabricação do papel e criar sérios problemas no processo, sendo assim é utilizado como medida de controle: o cloro (BRAILE; CAVALCANTI, 1979). Por isso, outra proposta de melhoria foi a reforma do Tanque de Desinfecção, tendo como mudanças o nivelamento do fundo do mesmo e reboco com pintura das paredes com tinta impermeável, para tornar a superfície mais lisa e minimizar a aderência de colônias de microrganismos nos orifícios do mesmo. A recuperação deste tanque traz como benefício o aumento da eficiência no que diz respeito à eliminação de microrganismos, pois eleva a atuação do agente bactericida sobre a água proporcionando a qualidade necessária do efluente tratado para recirculação. 


\section{Manutenção preventiva das bombas}

Eventualmente a recirculação de efluentes era interrompida devido a problemas mecânicos no sistema de bombeamento dos químicos. Diante disso, foi criada junto ao setor de manutenção, uma sistemática de manutenção preventiva, calculada com base no número de horas que cada equipamento trabalha no mês. Esta ação visou manter a qualidade no tratamento de efluentes e eliminar falhas nas bombas, o que poderia comprometer o processo de recirculação por falta ou excesso de produtos químicos dosados.

\section{CONCLUSÃO}

O desenvolvimento e utilização das matrizes para as análises foi um processo decisivo no resultado do projeto, tendo em vista que, o desenvolvimento destas matrizes apontou diversas variáveis do processo, em se tratando materiais, mão de obra, meio ambiente, máquina, métodos e medidas. A ferramenta do Diagrama de Pareto, bem como os 5 por quês e análise de causa raiz foram precisas na identificação dos modos de falha mais relevantes, contribuindo na sinalização das maiores oportunidades, com ganhos mais eficazes.

As maiores dificuldades para o reuso do efluente, estavam associadas aos critérios de formação de colônias de microrganismos ao longo do processo produtivo. Dessa forma, atuou-se na causa raiz para eliminar esta variável aumentando a eficiência do tanque de desinfecção, a fim de não comprometer o processo de tratamento de efluentes.

Ao mesmo tempo, a garantia da manutenção preventiva das bombas de dosagem para funcionamento constante na dosagem de químicos e a automatização da dosagem de químicos antes do efluente ser direcionado para o Tanque de Equalização na ETE, proporcionou uma maior estabilidade no parâmetro $\mathrm{pH}$.

Com isto, foi atingido o objetivo de aumentar o percentual de reuso de água e também uma maior estabilidade do processo de tratamento de efluentes, de média de recirculação e de volume de água bruta captada no corpo hídrico.

\section{REFERÊNCIAS}

BARROS, L. B. M. Seleção de materiais para redução de custos em uma máquina de papel "Tissue". 2006. 8 f. Artigo, Escola Politécnica da Universidade de São Paulo. São Paulo, 2006. Disponível em: <http://sites.poli.usp.br/d/pme260 0/2006/Artigos/Art_TCC_045_2006.pdf> Acesso em: 05 de out. 2014. 
BRAILE, P. M.; CAVALCANTI, José Eduardo W. A. Manual de tratamento de águas residuárias industriais. São Paulo: CETESB, 1979. 764 p.

CONAMA. Resolução CONAMA 430/2011. Diário Oficial da União, p. 9, 2011.

EDWARD D. ARNHEITER, J. M. The integration of lean management and Six Sigma. The TQM Magazine, v. 17, n. 1, p. 5-18, 2005.

MANCUSO, P. C. S.; SANTOS, H. F. Reuso de água. Barueri, SP: Manole, 2003. 579 p. (Coleção Ambiental).

MOUSA, A. Lean, six sigma and lean six sigma. Overview. International Journal of Scientific \& Engineering Research, v. 4, n. 5, p. 1137-1153, 2013.

NUNES, J. A. Tratamento biológico de águas residuárias. 3.ed. Aracaju: Gráfica Editora J. Andrade, 2012. $277 \mathrm{p}$.

SANTOS FILHO, D. F. Tecnologia de tratamento de água: água para indústria. 3 ed. São Paulo: Ed. Nobel, 1987. 251 p.

TELLES, D. D'A.; COSTA, R. H. P. G. Reuso da água: conceitos, teorias e práticas. São Paulo: Blucher, 2007. 311 p. 